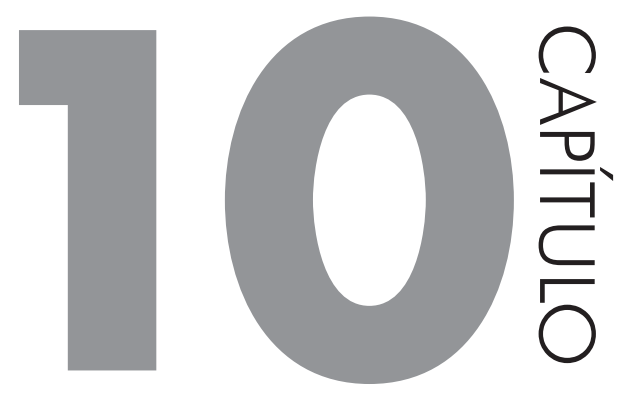

\title{
NOTAS SOBRE INTERDISCIPLINARIDADE NA FORMAÇÃO INICIAL DE PROFESSORES: UM RELATO DE CASO
}

\section{KARINA MARCON, ROSELAINE RIPA, SOLANGE CRISTINA DA SILVA}

\section{INTRODUÇÃO}

Com sede em Florianópolis - SC, o Centro de Educação a Distância da Universidade do Estado de Santa Catarina (Cead/Udesc) desenvolve atividades em nível de graduação, extensão, pesquisa e pós-graduação. No âmbito da graduação, desde 2011 oferece o Curso de Pedagogia em convênio com o Sistema Universidade Aberta do Brasil (UAB), tendo, nos anos de 2015 e 2016, graduado aproximadamente 1.000 pedagogos. Atualmente o curso atende aproximadamente 700 alunos, distribuídos no $2^{\circ}$ semestre de 2017, nas $1^{\mathrm{a}}, 5^{\mathrm{a}}$ e $7^{\mathrm{a}}$ fases.

Com ênfase nas Tecnologias de Informação e Comunicação, o curso de Pedagogia a Distância do CEAD/Udesc também aponta como princípio norteador a "Formação teórica interdisciplinar sobre o fenômeno educacional e seus fundamentos filosóficos, históricos, políticos e sociais, bem como sobre os conteúdos inerentes à Educação Infantil, aos Anos Iniciais do Ensino Fundamental”. (Udesc, PPC, 2009, p. 9)

Atualmente o Curso de Pedagogia do CEAD/Udesc trabalha com dois projetos pedagógicos, sendo que as turmas das $5^{\mathrm{a}}$ e $7^{\mathrm{a}}$ fase seguem um projeto e a turma da $1^{a}$ fase, outro. Em ambos os projetos a formação teórica interdisciplinar é pre- 
vista na composição dos eixos curriculares, e o PPC orienta, como uma das finalidades do curso, que as práticas pedagógicas estejam "subordinadas aos princípios de unidade e interdisciplinaridade dos conteúdos dos programas, à ação integrada dos docentes, e à relação entre teoria e a prática”. (Udesc, PPC, 2009, p. 9)

Desde 2014 o Núcleo Docente Estruturante e a Coordenação de Curso vêm dialogando sobre como seria possível expandir as discussões e efetivações de propostas pedagógicas interdisciplinares. Foi então que foi criada a figura do Coordenador de Fase, cujo papel principal era o de articular com as equipes da fase, propostas interdisciplinares entre disciplinas afins, bem como temáticas interdisciplinares que sejam discutidas por cada fase ao longo do semestre. Sobre essa questão, temos alguns relatos (Garcez, Carvalho \& Ripa, 2015; Garcez \& Ripa, 2015; Marcon, Malaggi, Moraes, Oliveira \& Ventura, 2016) que elucidam algumas das propostas interdisciplinares que já foram concretizadas até o momento.

Com a necessidade de reformulação do projeto pedagógico do curso, e levando-se em conta que as atuais Diretrizes do Conselho Nacional de Educação n. 01/2006, 05/2015 e a Resolução 002/2017 Consepe/Udesc têm como foco a formação inicial para o exercício da docência na Educação Básica e demais áreas afeitas à Pedagogia, o egresso do curso de Licenciatura em Pedagogia na Modalidade a Distância do CEAD/Udesc deverá ter sólida formação teórico-prática e interdisciplinar a fim de que, a partir de uma visão crítica e reflexiva, atue numa perspectiva de promoção da cidadania e de construção de uma sociedade mais justa, equânime, igualitária.

Nesse contexto, a docência deve ser concebida de forma ampla, enquanto campo multidimensional de atuação do Pedagogo, bem como compreendida como ação educativa e processo pedagógico metódico e intencional, construído em relações sociais, étnico-raciais e produtivas inerentes à complexidade da organização das instituições educativas, cuja função social é de promoção de processos de humanização inclusivos. Assim, cabe ao profissional do magistério, dentre outras ações, atuar profissionalmente com compromisso e ética no exercício da docência, em processos de gestão de processos educativos e na organização e funcionamento de sistemas e instituições de ensino, fundamentando-se em princípios de interdisciplinaridade, contextualização, democratização, pertinência e relevância social e sensibilidade afetiva e estética. Além disso, é objetivo ensinar, com competência, conteúdos científicos de grandes áreas do conhecimento, de acordo com a base comum nacional, dentre outros: língua portuguesa, matemática, ciências, história, geografia e artes, de forma interdisciplinar, respeitando as especificidades do desenvolvimento humano, tais como as diferenças de natureza ambiental-ecológica, étnico-racial, de gênero, faixas geracionais, classes sociais, religiões, necessidades especiais e orientações sexuais (Udesc, PPC, 2017). 
Além destas anotações sobre interdisciplinaridade, contribui, ainda, para a constituição do perfil do egresso do curso de Pedagogia CEAD/Udesc, a ênfase dada na Matriz Curricular no importante papel pedagógico das Tecnologias de Informação e Comunicação e demais processos e artefatos midiáticos no contexto da educação contemporânea. De modo que, em diversas fases do curso, as disciplinas do currículo estejam voltadas à articulação entre processos pedagógicos, práticas interdisciplinares e tecnologias digitais de informação e comunicação (Udesc, PPC, 2017).

\section{INTERDISCIPLINARIDADE E FORMAÇÃO DOCENTE}

A discussão sobre a necessidade de efetivar propostas interdisciplinares nos cursos de formação docente vem acontecendo ao longo das últimas décadas. Mesmo assim, poucas experiências têm sido propagadas nesse sentido no caso dos modelos pedagógicos para a educação a distância.

Fazenda (2006) ressalta que as discussões sobre interdisciplinaridade no Brasil se efetivam a partir da década de 1960, com diversas distorções em termos conceituais e práticos, refletindo a busca de novidades sem reflexão. Segundo a autora, alguns aspectos precisam ser evidenciados nessa retomada conceitual.

O primeiro aspecto refere-se ao modismo que o termo interdisciplinaridade desencadeou, motivando as reformas educacionais ocorridas entre 1968 e 1971 na Educação Básica. O segundo refere-se ao progresso que tiveram os estudos sobre interdisciplinaridade na década de 1970, mas que não evitaram a disseminação indiscriminada de práticas intuitivas das décadas de 1990 diante da constatação dos educadores de que não é mais possível desconsiderar a importância do trabalho interdisciplinar como uma exigência da proposta atual de conhecimento e de educação.

Diante desse contexto de ampliação de projetos que se intitulam interdisciplinares, Fazenda (2006, p. 34) conclui que são frutos “(...) da intuição ou da moda, sem lei, sem regras, sem intenções explícitas, apoiando-se numa literatura provisoriamente difundida".

Sendo assim, parece que ainda é um desafio a mobilização das instituições para a efetivação de práticas interdisciplinares a partir de teorias e experiências científicas de forma a construir processos de ensino-aprendizagem na perspectiva interdisciplinar.

Em termos de fundamentação dessas discussões, inicialmente foi necessária uma maior aproximação da equipe docente do CEAD/Udesc dos conceitos de muldisciplinaridade, pluridisciplinaridade, transdisciplinaridade e interdisciplinaridade. Foram observados que esses conceitos têm em comum os processos de 
integração disciplinar e designam diferentes maneiras de articulação entre os campos de conhecimento e a relação entre os componentes curriculares (Garcez, Carvalho \& Ripa, 2015).

Em alguns estudos, os conceitos de multidisciplinaridade e pluridisciplinaridade são apresentados como sinônimos, embora alguns pesquisadores registram que a multidisciplinaridade traz em si uma temática comum, não necessitando uma relação entre as disciplinas, e a pluridisciplinaridade, além de prever uma temática comum, potencializa a cooperação e relação entre as disciplinas. Nesse contexto, o conceito de interdisciplinaridade ocuparia uma posição intermediária em relação à multidisciplinaridade ou pluridisciplinaridade e à transdisciplinaridade.

A transversalidade e a interdisciplinaridade são modos de se trabalhar o conhecimento que buscam uma reintegração de aspectos que ficaram isolados uns dos outros pelo tratamento disciplinar. Com isso, busca-se conseguir uma visão mais ampla e adequada da realidade, que tantas vezes aparece fragmentada pelos meios de que dispomos para conhecê-la e não porque o seja em si mesma. (Garcia, 2007, p. 1)

No contexto educacional, segundo Gattás e Furegato (2007, p. 89) a interdisciplinaridade

(...) é vista como um processo que envolve a integração e o engajamento de educadores. Trata-se de trabalho conjunto, com interação das disciplinas do currículo escolar entre si e com a realidade. Superando a fragmentação do ensino, chega-se à formação integral dos alunos para exercerem criticamente a cidadania, mediante uma visão global do mundo, favorecendo o enfrentamento de problemas complexos.

Retomando os estudos de Japiassu (2006), ressaltamos que a interdisciplinaridade não pode ser considerada apenas uma categoria do conhecimento, mas de ação, pressupondo, dessa forma, atitude. Nesse sentido, Fazenda (2003) aponta que o diálogo torna-se uma condição para eliminar as barreiras entre as disciplinas e as pessoas. "Hoje, mais do que nunca, reafirmamos a importância do diálogo, única condição possível de eliminação das barreiras entre as disciplinas. Disciplinas dialogam quando as pessoas se dispõem a isto (...)". (Fazenda, 2003, p. 50)

Esse pode ser considerado o primeiro passo para as alterações do PPC para a aprovação dos Seminários Integradores conforme será descrito na sequência, pois, tal como Fazenda (2003) destaca, a interação entre as pessoas é uma condição básica para um trabalho interdisciplinar pois ele depende da coparticipação, reciprocidade e mutualidade dos envolvidos. 
Segundo Alves (2013, p. 106), a interdisciplinaridade é (...) uma "nova" atitude frente ao conhecimento, na busca do sentido do saber, procurando superar a insatisfação que a fragmentação cria". Quando os professores reconhecem as relações que as disciplinas que lecionam possuem com as demais disciplinas da fase, com as disciplinas do curso e seu papel na formação do acadêmico, o reconhecimento da fragmentação do conhecimento tende a ser discutido e a busca da totalidade, mesmo utópica (Alves, 2013), provoca reflexões e possibilidades pedagógicas.

\section{MARCOS LEGAIS DA PROPOSTA PEDAGÓGICA}

A partir da concepção de interdisciplinaridade e respeitando as legislações vigentes, o PPC reformulado do Curso de Licenciatura em Pedagogia na Modalidade a Distância do CEAD/Udesc atende aos seguintes documentos legais (Udesc, PPC, 2017):

- Decreto n. 5.622, de 19 de dezembro de 2005, caracteriza a Modalidade de Educação a Distância $(\mathrm{EaD})$ regulamentando o art. 80 da Lei n. 9.394, de 20 de dezembro de 1996 (LDB).

- Decreto n. 5.773, de 9 de maio de 2006, dispõe sobre o exercício das funções de regulação, supervisão e avaliação de instituições de educação superior e cursos superiores de graduação e sequenciais no sistema federal de ensino. Observamos que o atual projeto tem convênio com a UAB/Capes.

- Decreto n. 6.303, de 12 de dezembro de 2007, altera dispositivos dos Decretos ns. 5.622, de 19 de dezembro de 2005, que estabelece as diretrizes e bases da educação nacional, e n· 5.773, de 9 de maio de 2006, que dispõe sobre o exercício das funções de regulação, supervisão e avaliação de instituições de educação superior e cursos superiores de graduação e sequenciais no sistema federal de ensino.

- Resolução CNE/CP n. 02/2002, institui a duração e as cargas horárias dos cursos de Licenciatura, de graduação plena, de formação professores da educação Básica em nível Superior.

- Resolução n. 01/2004, institui Diretrizes Curriculares Nacionais para a Educação das relações Étnico-Raciais e para o Ensino de História e Cultura Afro-Brasileira e Africana.

- Lei n. 11.788, de 25 de setembro de 2008, dispõe sobre o estágio de estudantes.

- RESOLUÇÃO CNE/CP n. 1, de 30 de maio de 2012, estabelece Diretrizes Nacionais para a Educação em Direitos Humanos. 
- Resolução CNE/CP n. 2, de 15 de junho de 2012, estabelece as Diretrizes Curriculares Nacionais para a Educação Ambiental.

- LEI N. 9.795, de 27 de abril de 1999, dispõe sobre a educação ambiental, institui a Política Nacional de Educação Ambiental e dá outras providências.

- Decreto n. 4.281, de 25 de junho de 2002, regulamenta a Lei no 9.795, de 27 de abril de 1999, que institui a Política Nacional de Educação Ambiental, e dá outras providências.

- Resolução CNE/CP n. 1, de 18 de fevereiro de 2002, institui Diretrizes Curriculares Nacionais para a Formação de Professores da Educação Básica, em nível superior, curso de licenciatura, de graduação plena.

- Lei n. 10.436, de 24 de abril de 2002, dispõe sobre A Língua Brasileira de Sinais e dá outras providências.

- Decreto n. 5.626, de 22 de dezembro de 2005, dispõe sobre a Língua Brasileira de Sinais - Libras.

- Resolução n. 025/2006 - Consepe, alterada pela Resolução n. 023/2013 - Consepe, dispõe sobre o valor do crédito, da duração do semestre letivo, da carga horária das disciplinas e dos cursos de graduação da Udesc.

- Resolução n. 026/2012 - Consepe, alterada pela Resolução n. 019/2013 - Consepe. Dispõe sobre as atividades complementares.

- Resolução n. 01, de 17 de junho de 2010 - Conaes, normatiza o núcleo Docente Estruturante e dá outras providências.

- Resolução n. 002/2017 Consepe, que define as diretrizes e bases conceituais curriculares para a formação inicial em nível superior dos cursos de licenciatura da Udesc e para a formação continuada em consonância com a Resolução CNE/CP n. 2, de $1^{\circ}$ de julho de 2015.

A partir destas diretrizes, o novo PPC foi para corresponder aos marcos legais vigentes, sendo que muitas das leis e resoluções foram atendidas por meio dos Seminários Integradores, disciplinas que acontecem em todas as fases do Curso de Pedagogia na modalidade a distância do CEAD/Udesc.

\section{OS SEMINÁRIOS INTEGRADORES COMO PROPOSTA DE CONSOLIDAÇÃO DA INTERDISCIPLINARIDADE NO CURSO}

A Udesc aprovou em 22 de fevereiro de 2017 a Resolução N. 002/2017 CONSEPE, que define as diretrizes e bases conceituais curriculares para a formação inicial em nível superior dos cursos de licenciatura da Udesc e para a formação continuada em consonância com a Resolução CNE/CP n. 2, de $1^{\circ}$ de julho de 2015. 
Em uma perspectiva interdisciplinar, essa resolução estabelece, no seu art. $5^{\circ}$, as bases conceituais comuns aos cursos de licenciatura da Udesc, a saber:

I - Escola e sociedade cujo objetivo é compreender a interdependência entre a escola e a estrutura social, bem como sua função social de sistematizar os conceitos científicos e disseminar a ciência e a cultura;

II - Organização da escola e trabalho docente cujo objetivo é compreender a escola como estrutura organizacional e seu funcionamento diante da legislação e das políticas educacionais vigentes, contemplando também a compreensão das dimensões éticas, políticas e estéticas necessárias para a organização do trabalho docente no que diz respeito aos saberes e fazeres da prática docente e o conhecimento das práticas pedagógicas nas diferentes modalidades de educação: Educação de Jovens e Adultos, Educação Especial, Educação Profissional e Tecnológica, Educação do Campo, Educação Escolar Indígena, Educação a Distância e Educação Escolar Quilombola;

III - Planejamento educacional cujo objetivo é conhecer os tipos de planejamento educacional e suas diferentes concepções e implicações na estrutura e funcionamento da escola;

IV - Currículo e cultura escolar cujo objetivo é conhecer as teorias curriculares e os processos sócio históricos constitutivos da cultura escolar;

V - Processos de ensino e aprendizagem cujo objetivo é conhecer epistemologicamente as diferentes concepções de ensino e aprendizagem considerando as temporalidades humanas: infância, adolescência, juventude, adultez e velhice; VI - Avaliação Educacional cujo objetivo é conhecer os processos de avaliação educacional compreendendo avaliação institucional, avaliação em larga escala e avaliação da aprendizagem;

VII - Infância, adolescência, juventude, adultez e velhice cujo objetivo é conhecer as diferentes temporalidades humanas compreendendo suas especificidades de desenvolvimento e aprendizagem;

VIII - Direitos humanos e multiculturalidade cujo objetivo é refletir sobre a diversidade étnico cultural e suas implicações na sociedade e na organização escolar destacando a importância das demandas por cidadania na contemporaneidade;

IX - Tecnologias educacionais cujo objetivo é refletir sobre o potencial pedagógico de recursos tecnológicos da cultura digital, oportunizando espaços de apropriação crítica, autoral e colaborativa das tecnologias digitais.

Cada uma dessas bases conceituais está permeando os currículos dos cursos de licenciatura a distância do CEAD/Udesc, nas diferentes fases, visando contribuir com a compreensão da educação como processo emancipatório e permanente 
e o reconhecimento da especificidade do trabalho docente, conforme Art. $5^{\circ}$ da Resolução CNE/CP no 02/2015.

Especificamente no currículo do Curso de Pedagogia (Udesc, PPC, 2017), temos, em todas as fases, os Seminários Integradores, que têm como objetivo promover articulações entre os saberes dos componentes curriculares previstos em cada fase do curso, numa perspectiva integradora e trans/interdisciplinar.

O seminário é concebido como uma prática pedagógica socializada, que necessita da participação de todos os integrantes, ou seja, uma atividade pedagógica, mediada pelo professor, na qual os acadêmicos irão estudar, investigar, refletir e discutir uma determinada temática. A proposta é superar a simples organização de tópicos a serem apresentados pelos acadêmicos, sem a mediação docente, e incentivar o debate, as reflexões e a apropriação de conhecimentos, integrando as disciplinas em cada fase do curso (Udesc, PPC, 2017).

Foram selecionadas 8 (oito) temáticas com potencial para provocar reflexões acerca do processo educacional, que evitassem a hierarquização das áreas de conhecimento e, ao mesmo tempo, garantissem as especificidades das disciplinas de cada fase. São elas:

- $1^{a}$ fase: educação, formação docente e leitura de mundo

Ementa: Prática educativa e sociedade. Educação, instrução e ensino. A educação nos seus aspectos sociais, históricos, políticos, econômicos e filosóficos. A formação docente no curso de Pedagogia. Compreensão crítica do ato de ler como leitura de mundo. Reflexão autobiográfica do processo educacional a partir das abordagens teóricas desenvolvidas no semestre.

- $2^{a}$ fase: direitos humanos, políticas públicas e multiculturalidade

Ementa: Fundamentação e gerações dos Direitos Humanos. Declaração Universal dos Direitos Humanos. Os Direitos Humanos e as Políticas Públicas. As organizações governamentais e os movimentos sociais na implementação de políticas públicas. Direitos da criança e do adolescente no currículo da educação básica. Diversidade cultural, religiosa, étnico-racial, geracional e de gêneros e suas implicações na sociedade e na organização escolar. Reflexão sobre a multiculturalidade considerando a pluralidade cultural num contexto de direitos e deveres.

- $3^{\mathrm{a}}$ fase: formação e profissionalização docente

Ementa: Desenvolvimento histórico da profissão docente. Compromisso ético-político da docência. A feminização e proletarização do magistério. Professor reflexivo e professor pesquisador. Reflexão sobre os desafios na formação e no exercício profissional a partir das abordagens teóricas desenvolvidas no semestre. 
- $4^{a}$ fase: educação, infância e tecnologia

Ementa: Infância e educação: concepções, políticas e práticas. Educação Infantil no contexto contemporâneo: características e legislação. Educação Lúdica. TIC's na Educação Infantil. Reflexão sobre os desafios da educação, infância e tecnologias partir das abordagens teóricas desenvolvidas no semestre.

- $5^{\text {a }}$ fase: planejamento e avaliação na educação infantil

Ementa: As diferentes concepções de avaliação e suas implicações no trabalho pedagógico escolar. As especificidades educacionais e pedagógicas da prática da docência com crianças de zero a seis anos. A documentação pedagógica como atitude de planejar, observar, registrar e avaliar o percurso da vida cotidiana nas instituições. Avaliação de contexto na e da Educação Infantil. Análise e reflexão das experiências teóricas e práticas da Educação Infantil.

- $6^{a}$ fase: educação para sustentabilidade

Ementa: A crise do mundo atual: dimensão ambiental/ecológica e outras dimensões da crise (social, econômica, política). As bases epistemológicas da crise atual. Desenvolvimento, desenvolvimento sustentável e sociedade sustentável. A Educação para a sustentabilidade e outras perspectivas educativas. Cultura e Sustentabilidade: ecologia dos saberes. A década das Nações Unidas da Educação para o Desenvolvimento Sustentável (EDS). Educação para o desenvolvimento sustentável ou educação para sustentabilidade: questões estratégicas e metodológicas.

- $7^{\mathrm{a}}$ fase: planejamento e avaliação no ensino fundamental

Ementa: As especificidades pedagógicas da prática da docência nos anos iniciais do Ensino Fundamental. Tipos de planejamento educacional e suas diferentes concepções e implicações na estrutura e funcionamento da escola. Ludicidade e interdisciplinaridade nos anos iniciais do Ensino Fundamental. Processos de avaliação educacional: larga escala, institucional e da aprendizagem. Limites e possibilidades das políticas de avaliação (ensino, docente, sistema) na contemporaneidade.

- $8^{\text {a }}$ fase: indissociabilidade entre ensino, pesquisa e extensão.

Ementa: Função social da universidade brasileira. Indissociabilidade ensino, pesquisa e extensão como princípio constitucional do ensino superior brasileiro. O princípio da indissociabilidade nas diretrizes do CNE e no Plano Nacional de Educação/2015 e CONAE/2014. Reflexão sobre indissociabilidade entre ensino, pesquisa e extensão e suas relações com os Trabalhos de Conclusão de Curso.

A proposta de seminários é uma alternativa possível para minimizar a fragmentação do conhecimento que acompanha a dinâmica curricular dos cursos de ensino superior. Assim, a previsão de seminários integradores em cada semestre 
tem potencial para desencadear um processo de ensino-aprendizagem mais orgânico, capaz de promover a articulação entre as unidades temáticas (componentes curriculares) e a totalidade curricular, favorecendo a integração entre teoria e prática (Udesc, PPC, 2017).

No caso específico da EAD, os seminários integradores podem contribuir para a realização de trabalhos colaborativos, enriquecimento e aprofundamento dos conhecimentos, diversificação dos estudos e socialização das experiências sociais, políticas, culturais e educativas propostas.

Por fim, os seminários integradores são disciplinas que acontecerão ao longo do semestre e podem se converter em unidade de tempo-espaço na estrutura curricular. Convertem-se em momento de interação de docentes e acadêmicos no processo de elaboração dos conhecimentos, ao mesmo tempo em que se torna lócus de discussão e diálogo interdisciplinar entre as diversas ciências da educação.

Os seminários serão realizados no Ambiente Virtual de Aprendizagem AVA, interdisciplinarmente, com problematizações que envolvam as disciplinas da fase, norteadas pela temática de cada um dos seminários, por meio de encontros síncronos e/ou assíncronos com os professores e acadêmicos, utilizando recursos do AVA, tais como: fóruns de discussão, glossário, questionário, laboratório de avaliação, dentre outros. Também poderão acontecer encontros presenciais, conforme planejamento da fase. Poderão, ainda, ser utilizadas as tecnologias digitais de rede e outros recursos da Web 2.0. (Udesc, PPC, 2017)

\section{A EXPERIÊNCIA DO SEMINÁRIO INTEGRADOR I - EDUCAÇÃO E LEITURA DE MUNDO EM 2017/02}

No segundo semestre de 2017 a disciplina Seminário Integrador I - Educação e Leitura de Mundo, da $1^{\text {a }}$ fase do curso de Pedagogia na modalidade a distância do Cead/Udesc, foi oferecida a 03 turmas/polos no Estado de Santa Catarina, atendendo 128 alunos. Paralelamente ao Seminário, os alunos cursavam as seguintes disciplinas: Introdução à Pedagogia, Filosofia da Educação, História da Educação, Sociologia da Educação e Leitura e Produção Textual.

Com o objetivo central de refletir sobre os aspectos sociais, históricos, políticos, econômicos e filosóficos da educação e suas relações com a formação do pedagogo e com a docência na Educação Básica, o planejamento didático do Seminário Integrador I, no AVA, foi organizado em tópicos temáticos constituídos de orientações de estudo e atividades de aprendizagem. Nesse sentido, os tópicos foram assim intitulados e estruturados: 
a) Primeiro Tópico - Compreensão crítica do ato de ler como leitura de mundo

Este tópico referiu-se ao primeiro tema de estudo previsto no programa da disciplina SI-I em que o objetivo central era possibilitar ao estudante a compreensão crítica do ato de ler como leitura de mundo. A sua organização didática envolveu orientações de estudo com indicação de leitura obrigatória e participação em fórum de discussão, com postagem individual dos estudantes sobre suas memórias dos estudantes com relação à leitura de mundo e palavra. O período de estudo desse tópico compreendeu 03 semanas.

\section{b) Segundo Tópico - Prática Educativa e Sociedade}

O objetivo de aprendizagem deste tema foi analisar as relações entre práticas educativas e sociedade contemporânea, compreendendo seus aspectos sociais, históricos, políticos, econômicos e filosóficos da educação, além de investigar as concepções de educação, instrução e ensino. A organização didática envolveu orientações de estudo com indicação de quatro leituras obrigatórias e participação em uma atividade avaliativa online, um Glossário, desenvolvido a partir das leituras indicadas no tópico. O Glossário teve objetivo de aprofundar nossos conhecimentos sobre os termos e conceitos utilizados pelos autores nos textos e seus significados. O período de estudo desse tópico aconteceu em 04 semanas.

\section{c) Terceiro Tópico - Prática e Profissão Docente}

O objetivo deste tópico de estudo foi discutir os principais desafios relacionados à prática e profissão docente e ao ofício do professor. A proposta foi a realização de uma reflexão autobiográfica sobre o processo educacional a partir das abordagens teóricas estudadas ao longo deste semestre. A organização didática envolveu orientações de estudo com indicação de três leituras obrigatórias e participação em uma atividade avaliativa online, que solicitava a criação de um Power Point preparatório para a apresentação do Seminário avaliativo presencial, cujos temas versavam sobre os tópicos I, II ou III da disciplina: 1. Compreensão crítica do ato de ler como leitura de mundo; 2 . Prática educativa e sociedade e 3. Prática e Profissão docente. Os temas foram sorteados e cada grupo deveria escolher um assunto dentro do tema maior para apresentar no seminário. O período de estudo desse tópico aconteceu em quatro semanas.

d) Quarto Tópico - O Curso de Pedagogia

O tópico 4 teve como objetivo problematizar a formação docente no curso de Pedagogia. A proposta era que os estudantes fizessem uma reflexão sobre a docência, o pedagogo e o contexto educativo escolar. O tópico compreendeu um período de três semanas, nas quais foram indicadas três leituras obrigatórias. Este tópico não teve atividade avaliativa, apenas participação em fórum sobre os assuntos que estavam sendo estudados. 
e) Quarto Tópico - Narrativa autobiográfica do processo educacional a partir das abordagens teóricas desenvolvidas no semestre

O tópico 5 da disciplina teve como objetivo refletir autobiograficamente sobre o processo educacional a partir das abordagens teóricas desenvolvidas no semestre. Para o desenvolvimento da última unidade de estudos, que aconteceu simultaneamente à realização dos seminários avaliativos presenciais nos polos, os estudantes foram orientados a realizar a leitura de dois textos obrigatórios e a participação em uma autoavaliação, compreendendo um total de quatro semanas do curso.

Com relação aos seminários avaliativos presenciais, os mesmos aconteceram em cronograma específico em cada polo. Cada grupo teve um total de 10 minutos para apresentar o seminário. Ao final foi feita uma discussão de fechamento envolvendo as temáticas discutidas, buscando mediar as reflexões e qualificar as interações dos estudantes.

Para encerramento do semestre, foi unânime a decisão da equipe docente da $1^{a}$ fase em realizar um seminário interdisciplinar, cuja temática escolhida foi "A importância do ato de ler na formação do Pedagogo(a)", que culminou com os estudos realizados na disciplina Seminário Integrador I - Educação e Leitura de Mundo. Neste seminário, os professores da $1^{a}$ fase, em duplas ou em trios, foram presencialmente aos polos para abordar de forma interdisciplinar as discussões elegidas. Ressalta-se a adesão dos estudantes na referida proposta, bem como os feedbacks positivos recebidos pelos estudantes neste momento de diálogo interdisciplinar com a equipe docente.

\section{CONSIDERAÇÕES FINAIS}

Apesar dos estudos e discussões sobre a interdisciplinares estarem presentes no campo da educação nas últimas décadas, ainda é preciso avançar nas experiências envolvendo a interdisciplinaridade nos cursos de formação inicial dos professores, não apenas como conteúdo, mas em termos de organização e proposta curricular. Um desafio que tende a ser intensificado na modalidade a distância, devido a ampliação da oferta em diferentes turmas e polos de apoio presencial, a necessidade de envolvimento de diferentes equipes e ao uso das tecnologias da informação e comunicação para seu desenvolvimento. Fazenda (2006) ressalta que as discussões sobre interdisciplinaridade no Brasil se efetivam a partir da década de 1960, com diversas distorções em termos conceituais e práticos, refletindo a busca de novidades sem reflexão. Segundo a autora, alguns aspectos precisam ser evidenciados nessa retomada conceitual.

No Cead/Udesc, em especial no Curso de Pedagogia a Distância, a interdisciplinaridade tem sido foco das discussões pedagógicas desde 2014, envolvendo 
as coordenações pedagógicas, o Núcleo Docente Estruturante e as equipes docentes. Essas discussões culminaram nas alterações dos Projetos Pedagógicos do Curso de Pedagogia, atendendo a legislação vigente e ao que já era previsto no PPC. Com a proposta dos Seminários Integradores buscou-se uma forma de articular as disciplinas que estavam sendo oferecidas em cada fase, promovendo uma maior integração entre elas, de forma que fossem construídos conhecimentos novos e interdisciplinares.

A experiência em andamento do Seminário Integrador I - Educação e Leitura de Mundo, desenvolvido com as 03 turmas da $1^{\text {a }}$ fase do Curso de Pedagogia a Distância Cead/Udesc, tem demonstrado que a interdisciplinaridade pode acontecer quando há diálogo entre os docentes, avaliação das ações das disciplinas ao longo do semestre e uma relação entre o planejamento coletivo e a autonomia docente. Assim, a proposta é caminharmos para conseguir cada vez mais uma "nova" atitude frente ao conhecimento, motivada pela insatisfação que a fragmentação curricular cria, tal como destacamos ao citar Alves (2013). Esperamos, assim, que todos os envolvidos no processo de ensino-aprendizagem do Curso de Pedagogia do Cead/Udesc reconheçam as relações que as disciplinas que lecionam possuem com as demais disciplinas da fase, bem como o papel articular dos Seminários Integradores e reconheçam a contribuição dessa proposta para a formação do acadêmico.

\section{REFERÊNCIAS}

Alves, A. (2013). Interdisciplinaridade e matemática. In: Fazenda, I. C. A. (org.). O que é interdisciplinaridade? 2. ed. São Paulo: Cortez.

Fazenda, I. C. A. (2003) Interdisciplinaridade: qual o sentido? São Paulo: Paulus.

Fazenda, I. C. A. (2006). Interdisciplinaridade: história, teoria e pesquisa. 13. ed. São Paulo, Papirus.

Garcia, L. A. M. (2007). Transversalidade e interdisciplinaridade. Disponível em: $<$ http://smeduquedecaxias.rj.gov.br/nead/Biblioteca/Forma\%C3\%A7\%C3\%A3o\%20 Continuada/Artigos\%20Diversos/garcia-transversalidade-print.pdf $>$. Acesso em: 10 ago. 2015.

Gattás, M. L. \& Furegato, A. R. F. (2007). A Interdisciplinaridade na Educação. In: Rev. RENE. Fortaleza, v. 8, n. 1, p. 85-91, jan./abr. 2007. Disponível em: <file://C:/Users/ pgabrieladutra/Downloads/645-2362-1-PB\%20(1).pdf>. Acesso em: 9 ago. 2015.

Garcez, A. F., Carvalho, G. M. D. \& Ripa, R. (2015). Proposta Pedagógica Interdisciplinar: relato de experiência do curso de Pedagogia a Distância do CEAD/Udesc /UAB. In: Sousa, A. H. de, Pandini, C. M. C., Bleicher, S., Tridapalli, A. L., Serra, 1. M. R. de S., Rauski, E. F. et al. (Orgs.). (2015). Práticas de EaD nas universidades estaduais e municipais do Brasil: cenários, experiências e reflexões. Florianópolis: Udesc. 
Japiassu, Hilton. (2016). O sonho transdisciplinar e as razões da filosofia. Rio de Janeiro: Imago.

Marcon, Karina, Malaggi, Vitor, Moraes, Marta Corrêa, Oliveira, Edna Araújo S. \& Ventura, Lidnei. (2016). A importância do ato de ler na formação do Pedagogo: uma experiência interdisciplinar. In: XIII Congresso Brasileiro de Ensino Superior a Distância e do II Congresso Internacional de Educação Superior a Distância, 2016, São João del-Rei: UFSJ, 2016. p. 2147-2156.

UDESC. (2009). Projeto Pedagógico do Curso (PPC) de Pedagogia do Cead/Udesc. Florianópolis: Udesc.

UDESC. (2017). Projeto Pedagógico do Curso (PPC) de Pedagogia do Cead/Udesc. Florianópolis: Udesc. 